\title{
The Simulation Model of Fixed Assets Reproduction of Mechanical Engineering Enterprises
}

\author{
Vladislav V. Kukartsev \\ (a) Dept. of Informatics \\ Siberian Federal University \\ (b) Dept. of Information Economic \\ Systems \\ Reshetnev Siberian State University of \\ Science and Technology \\ Krasnoyarsk, Russia \\ vlad_saa_2000@mail.ru
}

\author{
Andrei A. Boyko \\ (a) Dept. of Management \\ Siberian Federal University, \\ (b) Dept. of Management \\ Reshetnev Siberian State University of \\ Science and Technology \\ Krasnoyarsk, Russia
}

\author{
Oleslav A. Antamoshkin \\ (a) Dept. of Information Technologies in \\ Creative and Cultural Industries \\ Siberian Federal University \\ (b) Dept. of Information Economic \\ Systems \\ Reshetnev Siberian State University of \\ Science and Technology \\ Krasnoyarsk, Russia
}

\begin{abstract}
This article represents a description of the model of a reproduction of fixed assets (FA) of the enterprise in natural form, which is a tool for automating the process of developing a strategy for the progress of a machine-building enterprise fixed assets. The process of reproduction of the enterprise's FA is a socio-economic, complex, artificial, controlled, dynamic, discretecontinuous, stochastic, and open system. The methodology of system analysis was applied to analyze systems of this class, using the principles as follows: purposefulness, detachment, decomposition, functionality, and development. These principles of system analysis are formalized in the form of a complex of various models such as canonical; hierarchical; the composition of system elements; internal structure; functioning and development of the system. This article also shows an imitationdynamic model of the reproduction of machines and equipment of a machine-building enterprise. The model is developed on the basis of the method of system dynamics and tools of Powersim Studio, which is integrated into the widely used ERP system Sap $R / 3$. The model shown is basic and simulates the process of reproducing equipment in natural form. The model was used as an automation tool for researching various variants of the reproduction of machines and equipment in a machine-building enterprise. The research done allows drawing a conclusion that the built simulation-dynamic model is quite universal and on its basis, it is possible to do various researches concerning various aspects of reproduction of the equipment of the enterprises.
\end{abstract}

Keywords-reproduction of fixed assets, machine-building enterprises, system dynamics

\section{INTRODUCTION}

Automation is one of the modern directions of scientific and technological progress, based on self-regulating technical means and mathematical methods for freeing a person from participating in the processes of obtaining, converting, transferring and using energy, materials, products or information, or significantly reducing the degree of this participation or the laboriousness of the operations [1-4]. One of the most popular mathematical methods today, used as a tool for automating production, transportation, logistics and other processes is system dynamics simulation modeling. [5]
System dynamics simulation modeling is a method of investigation where the real system or process being studied. It is represented by a model sufficiently adequate to display the system or process on which experiments are performed to obtain data about the system or process. The constructed model is being "played" in time. [6-10]

The article describes the system dynamics simulation model of the reproduction process of the machine-building enterprises basic production assets, on the basis of which it is possible to automate the process of developing a strategy for the growth of the company's fixed assets. [11]

The size and the main technical condition of the fixed assets (FA) considerably define the set of technical and economic indicators of the organizations, such as the power, the level of quality and competitiveness of production, the degree of efficiency of use of resources and prime cost. The resulting effects of the activity of the organization depend on as far as organization is provided with fixed assets. $[7,9,12]$

The condition of fixed assets, their compliance to modern scientific and technical achievements are formed in the course of their reproduction defining the choice of the forms of compensation of wear, methods, and rates of updating of FA and also the efficiency of their use. The fixed assets of the organizations are characterized by the long period of operation. Therefore, the questions of strategic planning of reproduction processes on prospect have the paramount importance.

That's why the developing the strategic plan of reproduction of FA of the organization requires the use of effective techniques of support of the adoption of decisions, both for the set planning period and in case of unexpected change of the calculated planned values. The process of reproduction of FA is the difficult system, and the application of such techniques is almost impossible without the use of the special computer models for the analysis of the efficiency of the plan taking into account opportunities of his expeditious adjustments. 


\section{LITERATURE REVIEW}

Nowadays, the method of the imitating and dynamic modeling (IDM) at a research behavior of big and difficult systems gets a wide use. In the middle of $50 \mathrm{~s}$, Jay Forrester offered of system dynamics [4] is used for the solution of problems of the strategic level of business management in IDM [13-16].

All process of creation of model [6, 9] of system dynamics can be divided into a number of stages: the content description of a modeling subject, the problem definition and the formation of the goals; the creation of the causal relationship diagram, the definition of the polarity of relations and the contours of the causal relationship; the construction of the diagram of the stream and levels based on the diagram of the causal relationship; the translation of the chart of streams and levels in a mathematical form, i.e. writing of the equations of dynamics of the model; the verification of the model, the check of model's adequacy. [17, 18]

\section{PROBLEM STATEMENT}

This article represents the description of the model of a reproduction of FA of the enterprise in a natural form. The process of reproduction of FA of the enterprise is the social and economic, difficult, artificial, operated, dynamic, discrete and continuous, stochastic, open system. The research of such class systems requires the application of the methodology of the system analysis. It is necessary to follow the general principles such as focus, isolation, functionality, and development. The specified principles of the system analysis are formalized in the form of a complex of various models [19]: initial, hierarchical, structure of elements of the system, internal structure, functioning and development of system [20].

The purpose of reproduction of FA consists in providing the existence in necessary time in a certain place of labor instruments with such consumer properties which correspond to market requirements in quantitative and qualitative parameters of a certain product. Therefore, the purpose of reproduction of labor instruments is the ensuring of the sufficient size of power.

For the reflection of the principle of the system isolation of the FA reproduction, the initial model is built. The initial model shows the interactions of investigated systems with the external environment by means of inputs and outputs (Fig. 1).

After the analysis of input and output factors of the process of FA reproduction of its internal structure is studied, i.e. the principle of the decomposition is applied. The internal structure of process is investigated with models of three types: hierarchical model, a model of the structure of system elements and model of internal structures [4, 8, 19].

The system of FA reproduction can be subdivided into three levels of hierarchy: levels $0,1,2$. As the top, zero level is the system of public reproduction of FA which includes all the stages of a cycle: the creation, the attraction, the use and the restoration of the labor instruments. On the first level, there is an individual reproduction of fixed assets, and reproduction at the level of the enterprise which consists of three stages: attraction, use, restoration. Lower, at the second level, the reproduction of FA in divisions of the organization consisting of such stages as the use and the partial restoration is located.

Next, we specify the structure model of the system elements. The circulation of the labor instruments is carried out on the following stages: the attraction (delivery and installation), the use (operation and maintenance), and the restoration (repair and modernization). The selected stages in the model elements of the system are finite elements of decomposition of the system of reproduction of the enterprise's FA and create a basis for constructing models of the internal structure. In the model of the internal structure, the relationships between the elements of the system during its functioning are reflected [20]. Usually, the type of communication (material, information, personnel, etc.) and the direction of communication (from where and where) are reflected only. The circulation of assets has two forms: natural and value. That's why to examine the internal structure of the process of reproduction of FA assumes, firstly, the relationship between models of internal structure in natural and value forms and, secondly, the links within each model.

There are only informational links between models in the natural and value form exist in the aggregated model of the internal structure of reproduction of FA (Fig 1): data of the required quantities by available technological groups; data of the number of equipment under repair; data of the average service life of equipment; data of the number of purchased new equipment; data of the number of outgoing equipment. There are only material and information communications in the model of the internal structure of the FA reproduction (Fig. 2) between the stages of the process.

The description of the dynamic model of the FA reproduction submitted further is based on the model of the internal structure. At the stage of "use" of FA, the consumption value during their operation reduces and transfer of the cost on a product and on the rendered services. During the productive use the physical deterioration of the labor instruments, the gradual loss of the use value and value occur. Physically wornout labor instruments pass to the repair and modernization stage. It's called the stage of "restoration". At this stage, according to the scheduled preventive maintenance, the set of the planned organizational and technical actions on current and capital repair of FA realizes. The main objective of these actions is the prevention of progressively increasing deterioration, the prevention of accidents and the support of FA in the condition of constant availability for service. After the implementation of the repair or modernizations, the equipment comes back to operation.

This process happens until the equipment isn't completely worn out, and its cost is completely postponed for the made product or services. After that, the equipment arrives on a stage of dismantling and elimination and leaves production process.

At a stage of "attraction" of FA instead of the leaving equipment, the new equipment is bought and delivered to the enterprise. The properties of new equipment are similar to the usual properties or higher. Further, the installation of this equipment (construction works and installation of the base, adjustment) takes place. And all the stages repeat again. 


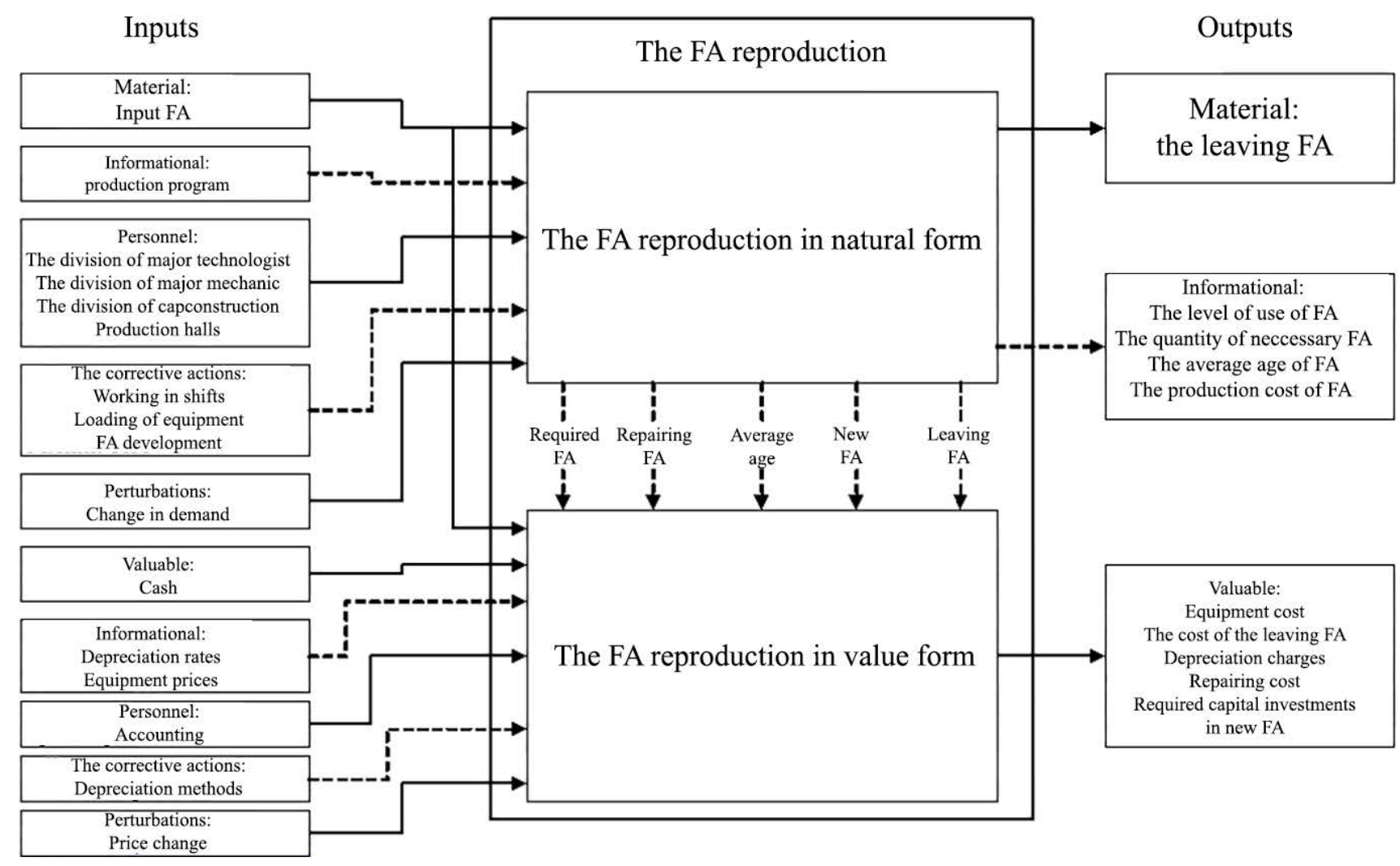

Fig. 1. The aggregated model of the internal structure of the FA reproduction

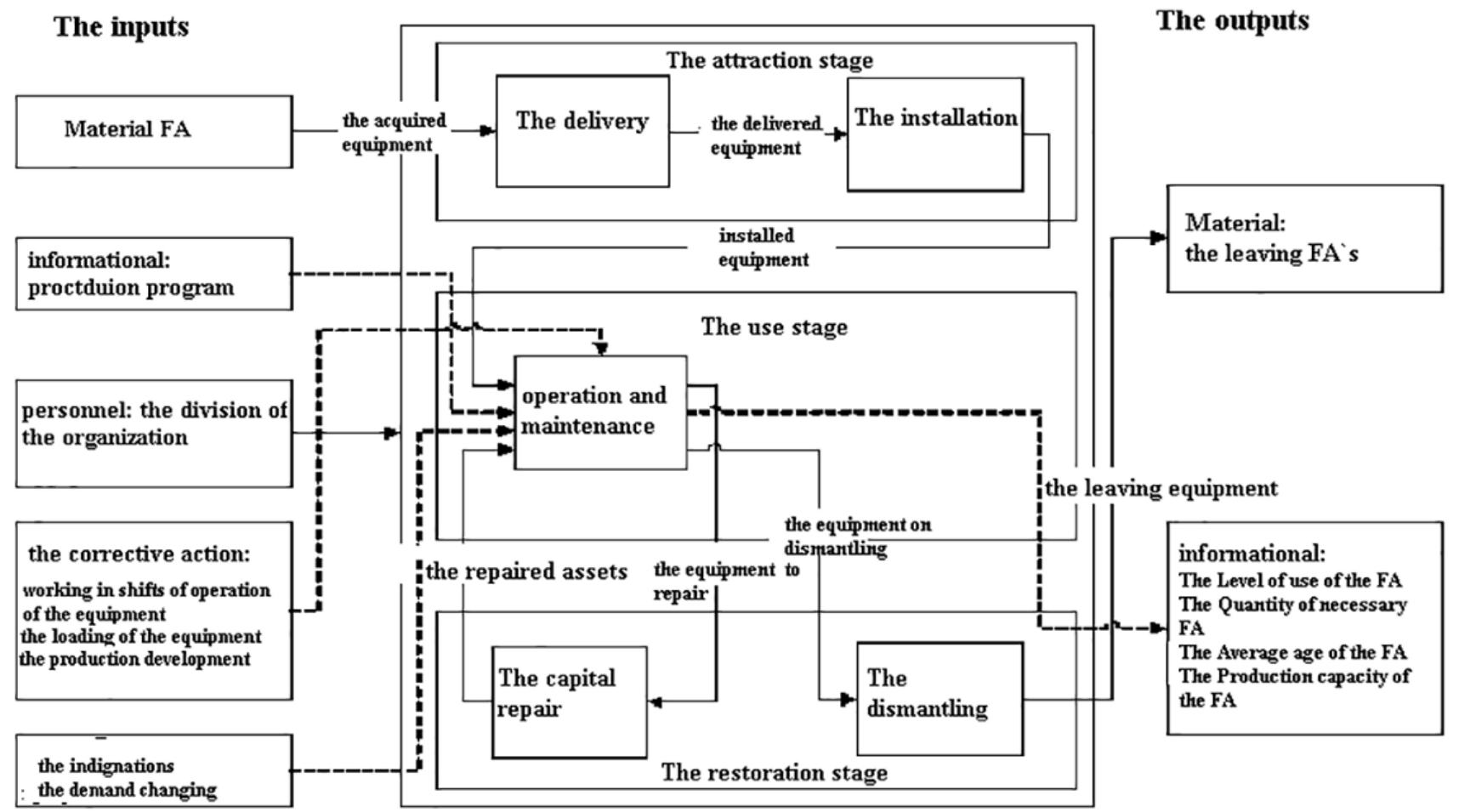

Fig. 2. The model of the internal structure of the FA reproduction 


\section{RESULTS}

The basis of the diagram of causal relationships of the model of the reproduction of FA of the enterprise in a natural form "Equilibration under the influence of a $\log$ of implementation of decisions" of (Fig. 3) makes a reflexive contour of the feedback $[9,10]$.

This contour is a contour of the negative feedback. It is interpreted as follows: the reproduction of FA of the machinery enterprise is guided by ensuring the necessary size of production capacity of the enterprise which has to correspond to the production program planned for a certain period. During the changing of the production program (growth or decrease) the gap between necessary production capacity and actual is forming. It is necessary to make decisions on corresponding change and production capacity. It can be in-creased in power due to the acquisition of the new equipment or power deceleration by elimination superfluous. But it is inexpedient to get or liquidate the FA at once. It is necessary to wait as the increase or the reduction of the quantity of the FA or respectively the production capacity due to the receipt or leaving from the repair equipment which has served the term.

Such delay is a delay of adaptation which allows to adapt the assets to the changes of the factors determined by the procedure of decision-making. The decision which is made will affect the current production capacity level of the enterprise not at once but with a delay in one step of the model time. The existence of the negative feedback and delay in the decision-making is led to oscillatory type of behavior of the provided contour.

This contour is a contour with the limit cycles of fluctuations, it has global stability, i.e. the trajectory of fluctuations of the system does not disperse indefinitely. At the same time, the system is locally unstable, because of the weak indignations (the planned growth of the production program, the elimination of the served equipment, etc.) rejecting the sys-tem from a balance point.

The diagram of streams and levels of the FA reproduction in a natural form and the leading rules of its regulation are schematically submitted in Fig. 4.

Let's give the mathematical description of the main equations of the model dynamics after the creation of the chart of streams and levels. Let's begin the description with a contour of a stream of FA containing the delay caused by their installation.

$$
\begin{gathered}
N_{\text {insti }}(t)=N_{\text {insti }}(t-\Delta t)+\Delta t *\left(P_{\text {com }}(t-\Delta t)\right) \\
P_{\text {com }}(t-\Delta t)=D E L A Y M T R\left(P p(t-\Delta t) ; t_{\text {com }} ; 3 ; \text { initial }\right)
\end{gathered}
$$

where "i" is the number of the certain technological group; $\mathrm{N}_{\text {insti }}$ is the quantity of the FA of the technological group in installation, in units; $\mathrm{P}_{\text {com }}$ is the rate of the FA commissioning of the technological group, units per week;
DELAYMTR is the equation of the third order delay; $t_{b b}$ is the delay of the FA input, in weeks.

The equation (1) determines the level of the equipment undergoing the installation. The equation (2) describes the process of the installation of the FA. Here the delay reflects the time for the installation of the base for the equipment, the installation of the machines and their adjustment.

The number of the equipment, which is in operation is defined by the equation of the level:

$$
\begin{gathered}
\text { Noperi }(t)=\text { Noperi }(t)+\Delta t \times(P c o m(t-\Delta t)-P d e c(t-\Delta t)- \\
\operatorname{Prrep}(t-\Delta t)+P \text { Pi }(t-\Delta t))-P d e c e(t)
\end{gathered}
$$

where $N_{\text {operi }}$ is the quantity of the FA of the technological group in operation, in units; $P_{d e c}$ is the rate of the leaving of the FA of the technological group, units per week; $P_{\text {rrep }}$ is the rate of the receipt of the FA of the technological group in repair, units per week; $P_{p i}$ is the rate of the commissioning of the FA of the technological group after repair, units per week; $P_{\text {dece }}$ is the rate of the leaving of the excess equipment of the technological group, in units.

The number of the equipment which is under repair is defined by the equation of the level: number of the equipment,

$$
\operatorname{Nrepi}(t)=\operatorname{Nrepi}(t-\Delta t)+\Delta t) *(\operatorname{Prrer}(t-\Delta t)-\operatorname{Ppi}(t-\Delta t))(4)
$$

$\mathrm{N}_{\text {repi }}$ is the number of the equipment of the technological group under repair, in units.

The number of the equipment which is in dismantling is defined by equation of the level:

$$
N \operatorname{dec}(t)=\operatorname{Ndec}(t-\Delta t)+\Delta t) *(\operatorname{Pdeci}(t-\Delta t)-P \operatorname{disi}(t-\Delta t))(5)
$$

$\mathrm{N}_{\text {dec }}$ is the number of the dismantling equipment of the technological group, in units; $\mathrm{P}_{\text {disi }}$ is the rate of the write-off of the equipment of the technological group, units per week.

Now let's address to the consideration of some provisions defining the necessary number of the equipment for the implementation of the production program:

$$
N_{n e c}(t)=\frac{T_{i}(t)}{F r(t) * k l i * k p e r i(t) * k n i(t)}
$$

where $\mathrm{N}_{\text {nec }}$ is the number of the equipment of the technological group that is necessary for the implementation of the production program, in units; $T_{i}$ is the planned production program of the equipment technological group, machine hour per year; $F_{r}$ is the valid annual asset of the operating time of the equipment unit, machinehour/year/unit; $\mathrm{k}_{\mathrm{li}}$ is the coefficient of the loading of the equipment of the technological group; $\mathrm{k}_{\text {peri }}$ is the performance level of the equipment of the technological group comparing to the initial level, in $\% ; \mathrm{k}_{\mathrm{ni}}$ is the coefficient of the technological group equipment progressiveness. 
2018 International Russian Automation Conference (RusAutoCon)

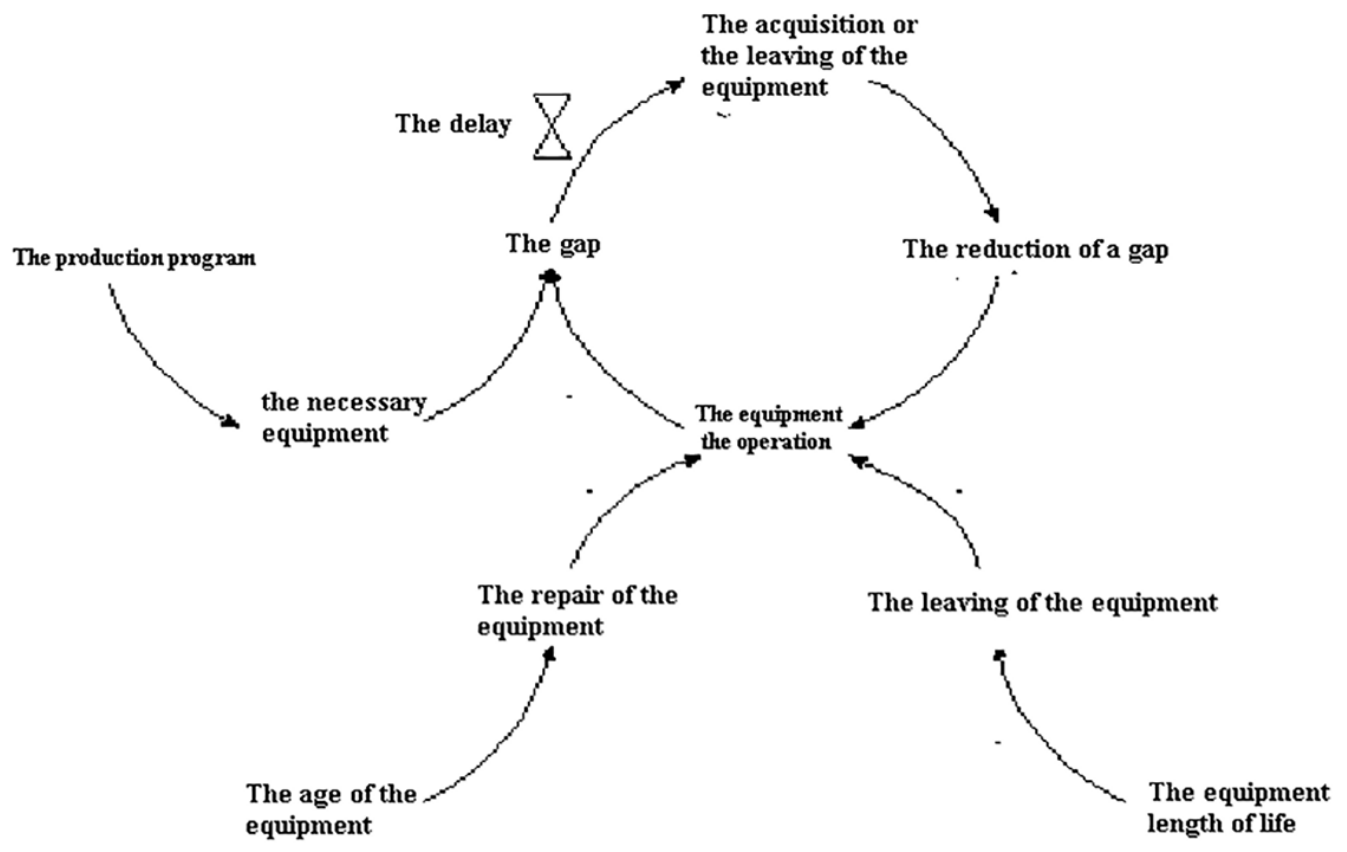

Fig. 3. The diagram of the causal relationship of the FA reproduction

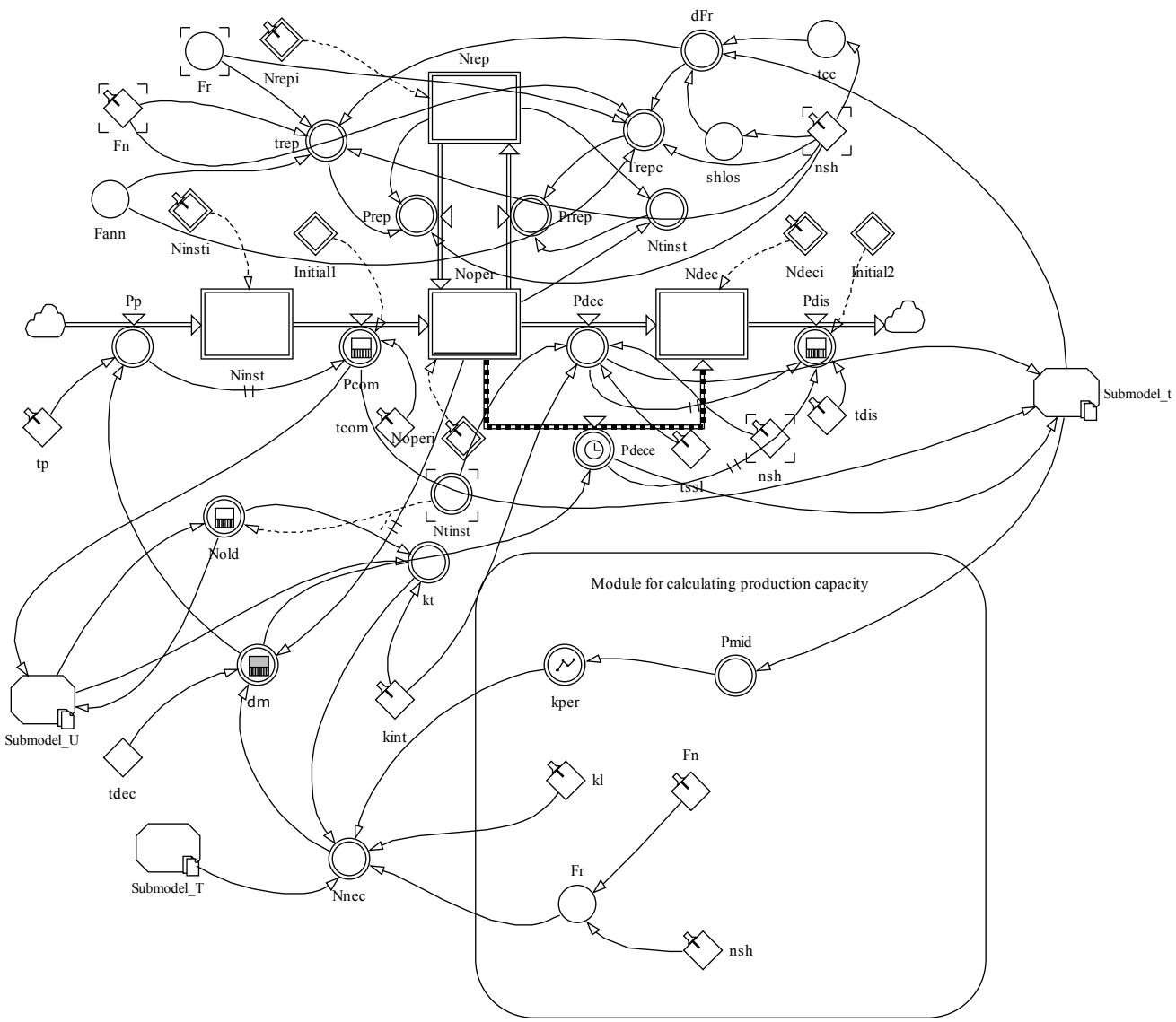

Fig. 4. The diagram of streams and levels of the reproduction of the equipment 


\section{International Russian Automation Conference (RusAutoCon)}

The difference between the necessary number of the equipment and the number of the equipment which is in operation defines the surplus or the deficiency of the machine park:

$$
\Delta m i(t)=\operatorname{Nnec}(t)-\operatorname{Noperi}(t)
$$

where $\Delta \mathrm{m}_{\mathrm{i}}$ is the discrepancy of the necessary and the number of the operated equipment of the technological group, in units. As the decision of acquisition of the new equipment is making only in case of the positive values received at the solution of the equation (7),

$$
P_{p i}(t+\Delta t)=\left\{\begin{array}{l}
\Delta m_{i}(t), \text { if } \\
\Delta m_{i}(t)>0 \\
0, \text { if } \Delta m_{i}(t)<0
\end{array}\right.
$$

The rate of the elimination of the excess equipment is defined the same way

$$
P_{\text {decei }}(t+\Delta t)=\left\{\begin{array}{l}
0, \text { if } \Delta m_{i}>0 \\
-\Delta m_{i}(t), \\
\text { If } \Delta m_{i}(t)<0
\end{array}\right.
$$

The presented equations are basic for the model of reproduction of the organization's FA.

\section{CONCLUSION}

In conclusion, we want to note that the constructed simulating model of the equipment reproduction is a basic model. It is possible to add various submodels for the calculation of various characteristics or parameters to this model at automation of strategic planning process of enterprise's fixed capital development. The functioning of the basic reproduction model of the equipment of the machinery enterprise will be the source of initial information which can be transformed to any necessary kind for these parameters. It is also necessary to note that the developed model can be adjusted on any type of the enterprise, and it can be considered as standard.

\section{REFERENCES}

[1] M. Bauer and J. C. Schlake, "Changes to the automation architecture: Impact of technology on control systems algorithms," 22nd IEEE Int. Conf. on Emerging Technologies and Factory Automation (ETFA), pp. $1-8,2017$.

[2] L. Han, H. Zhang, Y. Zhang, and L. Zhang, "System dynamics modeling and simulation for global energy-economy-politics system," IEEE Conf. on Energy Internet and Energy System Integration (EI2), pp. 1-6, 2017.

[3] V. S. Tynchenko, E. A. Petrovsky, and V. V. Tynchenko, "The parallel genetic algorithm for construction of technological objects neural network models," 2nd IEEE Int. Conf. on Industrial Engineering, Applications and Manufacturing, pp. 1-4, 2016.

[4] V. S. Tynchenko, A. V. Murygin, O. A. Emilova, A. N. Bocharov, and V. D. Laptenok, "The automated system for technological process of spacecraft's waveguide paths soldering," IOP Conf. Series: Materials Science and Engineering, vol. 155(1), 2016.

[5] M. A. Stolyarova, O. L. Shulgaty, M. R. Dzagoeva, L. I. Bestaeva, and V. A. Kaitmazov, "Generalization of foreign experience in the reproduction and recording of fixed assets," Int. Journal of Applied Business and Economic Research, pp. 241-250.

[6] I. V. Oliynyk, "Fixed assets management in the frameworks of classical and contemporary theories," Actual Problems of Economics, no. 168(6), pp. 47-53, 2015.

[7] A. V. Kukartsev, K. I. Gorlevskiya, and I. V. Ogurchenok, "Management of innovative activity of the enterprise of the spacerocket industry on the basis of process approach," Economy and management of control systems, vol. 11, no. 1.3, pp. 358-367, 2014.

[8] K. I. Gorlevskiya, I. V. Ogurchenok, and A. V. Kukartsev, "Scientific approaches to management of business processes of the enterprise of the space-rocket industry," Current problems of aircraft and astronautics, vol. 2, no. 10, pp. 113-114, 2014.

[9] A. A. Boyko, V. V. Kukartsev, K. Y. Lobkov, and A. A. Stupina, "Strategic planning toolset for reproduction of machine-building engines and equipment," J. Phys.

[10] A. A. Stupina, A. A. Shigina, A. O. Shigin, M. V. Karaseva, and S. N. Ezhemanskaja, "Automated intellectual system with the shortduration nature of feedback," Life Science, 11, pp. 302-306, 2014.

[11] A. Muftinisa, R. Ginanjar, R. B. Wahyu, and N. Hadisukmana, "Development and implementation of fixed asset management system," Second IEEE Int. Conf. on Informatics and Computing (ICIC), pp. 1-6, 2017.

[12] K. I. Gorlevskiya and A. V. Kukartsev, "Regulation of innovative business processes of the enterprise of the space-rocket industry," Bulletin of the Siberian state space university of the academician M.F. Reshetnev, no. 1(53), pp. 194-198, 2014.

[13] J. L. Gissel, "A case of fixed asset accounting: Initial and subsequent measurement," Journal of Accounting Education, no. 37, pp. 61-66, 2016.

[14] Y. Vertakova, S. Klevtsov, and M. Klevtsova, "Technology of fixed assets assessment in investigating the stability of the industrial complex of the region," 26th Int. Business Information Management Association Conf. - Innovation Management and Sustainable Economic Competitive Advantage, pp. 3230-3236, 2015.

[15] L. Ye, "Research on enterprise fixed assets management based on $\mathrm{K}$ MEANS clustering algorithm," Agro Food Industry Hi-Tech, no. 28(3), pp. 2540-2544, 2017.

[16] K. I. Gorlevskiya, I. V. Ogurchenok, and A. V. Kukartsev, "Control algorithm of innovative business processes of the enterprise of the space-rocket industry," Bulletin of the Siberian state space university of the academician M.F. Reshetnev, no. 2(54), pp. 158-164, 2014.

[17] H. M. Nijam, "Motives for Reporting Fixed Assets at Revalued Amount: Evidence from a Developing Economy," Global Business Review, no. 19(3), pp. 604-622, 2018.

[18] G. S. Klychova, A. R. Zakirova, K. Z. Mukhamedzyanov, E. R Sadrieva, and A. S. Klychova, "Development of audit system for operations with fixed assets as a tool for efficiency improvement of social activity of the enterprise," Journal of Engineering and Applied Sciences, no. 12(19), pp. 4966-4973, 2017.

[19] A. V. Kukartsev and K. I. Gorlevskiya, "Instruments of management of business processes of the enterprise of the space-rocket industry in the competitive environment," no. 5(41), pp. 081-091, 2013.

[20] M. D. Mattei and N. Mattei, "Analysis of fixed and biased asset allocation rebalancing strategies," Managerial Finance, no. 42, pp. 42-50, 2016. 